\title{
Sequential Ugi reaction/base-induced ring closing/IAAC protocol toward triazolobenzodiazepine-fused diketopiperazines and hydantoins
}

\author{
Robby Vroemans ${ }^{\ddagger 1}$, Fante Bamba ${ }^{\ddagger 1,2}$, Jonas Winters ${ }^{1}$, Joice Thomas ${ }^{1}$, Jeroen Jacobs ${ }^{3}$, \\ Luc Van Meervelt ${ }^{3}$, Jubi John ${ }^{* 1,4}$ and Wim Dehaen*1
}

\section{Full Research Paper}

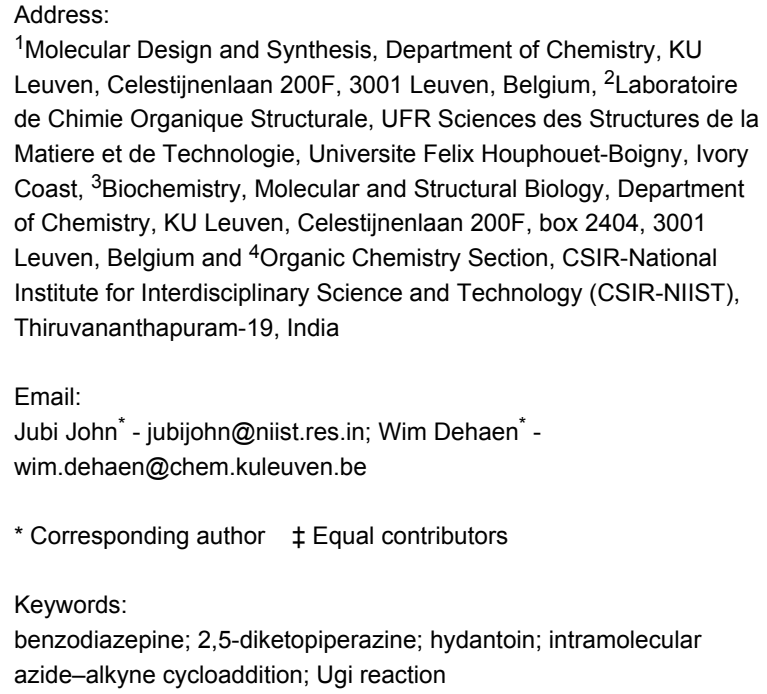

${ }^{1}$ Molecular Design and Synthesis, Department of Chemistry, KU Leuven, Celestijnenlaan 200F, 3001 Leuven, Belgium, ${ }^{2}$ Laboratoire de Chimie Organique Structurale, UFR Sciences des Structures de la Matiere et de Technologie, Universite Felix Houphouet-Boigny, Ivory Coast, ${ }^{3}$ Biochemistry, Molecular and Structural Biology, Department of Chemistry, KU Leuven, Celestijnenlaan 200F, box 2404, 3001 Leuven, Belgium and ${ }^{4}$ Organic Chemistry Section, CSIR-National Institute for Interdisciplinary Science and Technology (CSIR-NIIST), Thiruvananthapuram-19, India

Email:

Jubi John* - jubijohn@niist.res.in; Wim Dehaen* -

wim.dehaen@chem.kuleuven.be

* Corresponding author $\ddagger$ Equal contributors

\section{Keywords:}

benzodiazepine; 2,5-diketopiperazine; hydantoin; intramolecular azide-alkyne cycloaddition; Ugi reaction

\author{
Beilstein J. Org. Chem. 2018, 14, 626-633. \\ doi:10.3762/bjoc. 14.49 \\ Received: 20 December 2017 \\ Accepted: 22 February 2018 \\ Published: 14 March 2018 \\ Associate Editor: I. R. Baxendale \\ (c) 2018 Vroemans et al.; licensee Beilstein-Institut. \\ License and terms: see end of document.
}

\begin{abstract}
A practical three-step protocol for the assembly of triazolobenzodiazepine-fused diketopiperazines and hydantoins has been developed. The synthesis of these tetracyclic ring systems was initiated by an Ugi reaction, which brought together all necessary functionalities for further transformations. The Ugi adducts were then subjected to a base-induced ring closing and an intramolecular azide-alkyne cycloaddition reaction in succession to obtain highly fused benzodiazepine frameworks.
\end{abstract}

\section{Introduction}

The versatile bioactivities of multiring-fused heterocyclic scaffolds continue to attract significant attention in developing new methods for their synthesis. A plethora of functionalized fused heterocycles can be easily accessed by designing sequential organic transformations incorporating multicomponent reac- tions [1,2] combined with secondary transformations [3-11]. Over the past decade, several groups of chemists interested in synthetic chemistry have efficiently utilized the strategy of linking multicomponent reactions with intramolecular azide-alkyne cycloaddition (IAAC) for the generation of tri- 
azole-fused heterocycles [12-23]. In this report we disclose our results on the development of a sequential synthetic approach involving Ugi 4-component reaction (4-CR) and two ringclosing steps toward triazolobenzodiazepine-fused diketopiperazines and hydantoins.

Benzodiazepine derivatives [24,25] form an important class of 'psychoactive drugs' which is being extensively used in the treatment of anxiety, insomnia, agitation, seizures, muscle spasms, alcohol withdrawal, etc. [26-34]. In addition, these azaheterocycles also exhibit anti-inflammatory, antitumor, antiparasitic and anxiolytic activities [35-42]. In particular, 1,4-benzodiazepine derivatives are proposed to serve as a structural mimic of peptide $\beta$-turns [43-45] and are also known to bind to a number of biological targets [46-48]. Interestingly, the fusion of a triazole ring to a 1,4-benzodiazepine core has resulted in an increase in the biological activity as evident from the different drugs with triazolobenzodiazepine structure such as alprazolam, etizolam, triazolam, etc., available for the treatment of CNS related ailments (Figure 1) [49-55].<smiles>Cc1nnc2n1-c1ccc(Cl)cc1C(c1ccccc1)=NC2</smiles><smiles>Clc1ccc2c(c1)C(c1ccccc1)=NCc1nncn1-2</smiles>

estazolam

alprazolam<smiles>Cc1nnc2n1-c1ccc(Cl)cc1C(c1ccccc1Cl)=NC2</smiles>

triazolam
Figure 1: Triazolobenzodiazepine drugs.

Another set of heterocycles are 2,5-diketopiperazines, which form the core structure of many natural products and have recently been thoroughly studied for their wide spectrum of biological activities [56-58]. Owing to our interest in the chemistry of 1,2,3-triazoles [59-72] and the interesting biological ac- tivities of benzodiazepines and 2,5-diketopiperazines, we were motivated to develop a facile route towards multiring-fused derivatives incorporating all these heterocyclic moieties. We hypothesized that 2,5-diketopiperazine-fused triazolobenzodiazepine could be obtained by proper functionalization of building blocks starting with an Ugi reaction; followed by two ringclosing steps, one being a base-induced heterocycle formation and the other an IAAC. Unlike some of the reported strategies using $\mathrm{Cu}$-catalyzed IAAC $[13,15]$, we postulated that the intramolecular dipolar cycloaddition would proceed under thermal conditions (metal-free) due to the close proximity of the azide and similar functionalities in the intermediate. The functionalities required for the secondary transformations like the leaving group (-Cl) for nucleophilic substitution, alkyne and azide for IAAC can be assembled via the Ugi reaction (Scheme 1).

\section{Results and Discussion}

We initiated our studies with the Ugi 4-component reaction of $o$-azidobenzaldehyde (1a), propargylamine (2a), 2-chloroacetic acid (3a) and benzyl isocyanide (4a, Scheme 2). Initially, the condensation of the aldehyde and the amine was effected in $\mathrm{MeOH}$ in the presence of $4 \AA \mathrm{MS}$. This was followed by the sequential addition of chloroacetic acid and the isocyanide which, after 24 hours at room temperature, afforded the expected Ugi adduct $\mathbf{5 a}$ in $96 \%$ yield.

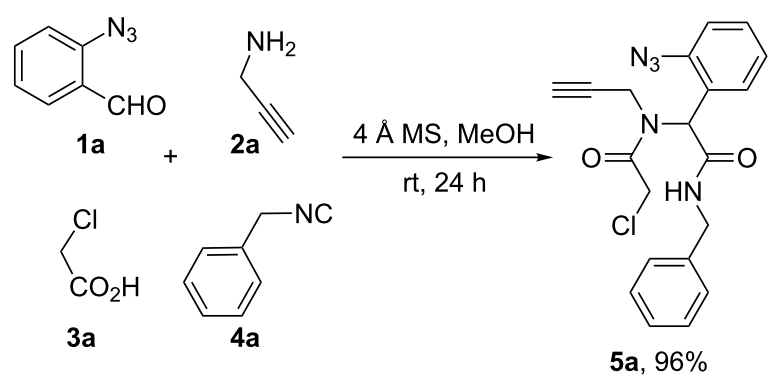

Scheme 2: Ugi 4-CR reaction.<smiles>[R]c1ccc2c(c1)-n1nncc1CN1C(=O)CN([R])C(=O)C21</smiles><smiles>[R][X]c1ccc(N)c(C2C(=O)N([R])CC(=O)N2CC#C)c1</smiles>
base-induced
ring closing<smiles>[R]NC(=O)C(c1ccccc1N)N(CC#C)C(=O)CCl</smiles><smiles></smiles><smiles></smiles>

$\mathrm{R}^{2}-\mathrm{NC}$ 
The synthesis of fused heterocycles from the Ugi adduct $5 \mathbf{a}$ was attempted via two routes (Scheme 3). The first route involved the base-induced cyclisation of $\mathbf{5 a}$ at the amide end by treatment with $\mathrm{KOH}$ from which the diketopiperazine moiety $\mathbf{6}$ was obtained in 51\% yield. Compound 6 bearing azide and alkyne functionalities was subjected to intramolecular azide-alkyne cycloaddition (IAAC) in EtOH at reflux conditions which afforded the target diketopiperazine-fused triazolobenzodiazepine $7 \mathbf{a}$ in $81 \%$ yield. The secondary path commenced with the intramolecular azide-alkyne cycloaddition of 5a which furnished the triazole-fused benzodiazepine 8 in $72 \%$ yield after 3 hours. The triazolobenzodiazepine 8 was then subjected to base-induced cyclisation with $\mathrm{KOH}$ which failed to afford the expected tetracyclic compound 7a. We believe that conformational restrictions prevent the side chains on the benzodiazepine bearing the amide and halogen to be in close proximity, which is needed for the reaction to proceed.

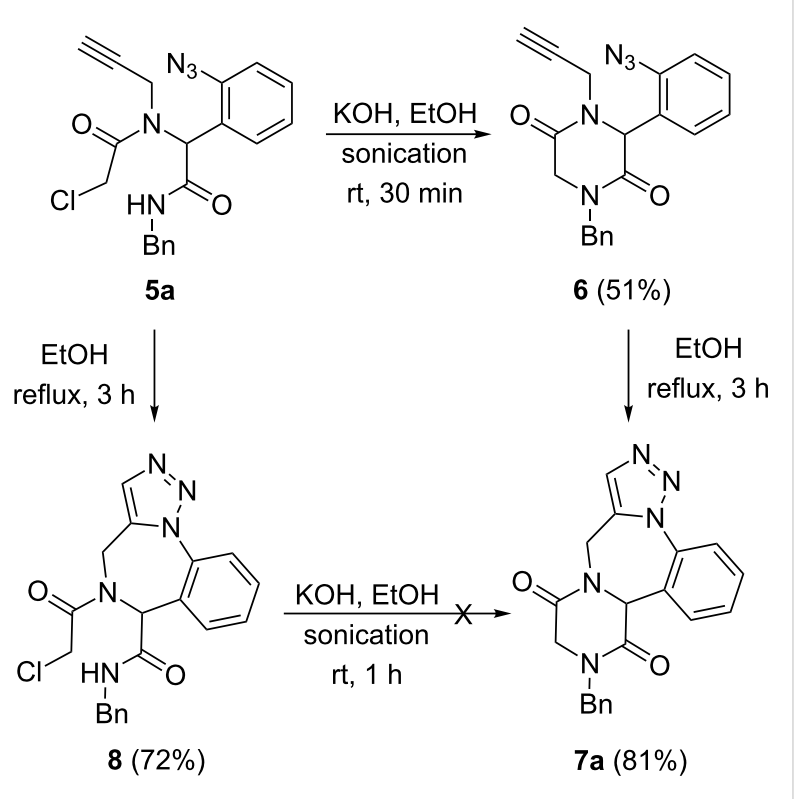

Scheme 3: Synthesis of diketopiperazine-fused triazolobenzodiazepine $7 \mathrm{a}$

The generality of the developed fused-heterocycle synthesis was studied with substituted azidoaldehyde, isocyanides and chloroacetic acid (Figure 2, see Supporting Information File 1 for full experimental data). In all the cases, the Ugi adduct precipitated from the reaction mixture within 24 hours, which was filtered, washed, dried and used as such without further purification. For all the examples, the ring-closing reactions were done in one-pot; which involved neutralization after base-induced diketopiperazine synthesis and dilution with EtOH before the IAAC step. Our first attempt was to study the effect of different substituents on the isocyanide (4a-d) moiety; from which we observed a slight decrease in the yield of the final product with increase in steric bulk of the substituent. Hence, an overall yield (over 3 steps) of 37\% was obtained for benzyl-substituted polycyclic compound $\mathbf{7 a}, 34 \%$ for $\mathbf{7 b}$ (cyclohexyl) and $27 \%$ for 7c (tert-butyl). p-Methoxyphenyl-substituted compound 7d was obtained in a good overall yield of $67 \%$. Next, we investigated the effect of the substitution pattern on the propargylamine 2 . For this, we chose easily available propargylamines $\mathbf{2 b}$ and $\mathbf{2 c}$ which gave moderate to good yields (60 and 40\%, respectively) of diketopiperazine-fused triazolobenzodiazepine $\mathbf{7 e}$ and $\mathbf{7 f}$. Furthermore, halogen substituents were introduced on polyfused heterocycles 7 because these were shown to often have a positive effect on the bioactivity (see compounds in Figure 1). Starting with 2-azido-4-bromobenzaldehyde (1b), we were able to prepare two brominated tetracyclic derivatives $7 \mathbf{g}$ and $7 \mathbf{h}$. In the same way, we were also successful in synthesizing chloro derivatives $7 \mathbf{i}$ and $7 \mathbf{j}$ from 2-azido-4-chlorobenzaldehyde (1c). The multiring-fused heterocycle synthesis was also tried with an azidobenzaldehyde bearing electron-donating substituents; the reaction with 2-azido-4,5-dimethoxybenzaldehyde (1d) yielded the product $7 \mathbf{k}$ in lesser yield (43\%). Finally, an additional stereocenter was introduced in the diketopiperazine ring by carrying out the Ugi reaction with 2-chloropropanoic acid (3b). After the sequential ring-closing steps the expected diketopiperazine-fused triazolobenzodiazepine 71 was obtained in $41 \%$ yield as a 1:0.7 inseparable mixture of diastereomers. Various attempts were made with other azidobenzaldehydes (5-azido-3methyl-1-phenyl-1H-pyrazole-4-carbaldehyde, 2-azidoquinoline-3-carbaldehyde and 2-azido-5-nitrobenzaldehyde) and isocyanides (2-morpholinoethyl isocyanide) towards the synthesis of diketopiperazine-fused triazolobenzodiazepine $7 \mathbf{m}-\mathbf{p}$. All of the mentioned substrates gave their respective Ugi adducts but the latter decomposed under basic treatment (in the case of 2-azidoquinoline-3-carbaldehyde, 2-azido-5-nitrobenzaldehyde, 2-morpholinoethyl isocyanide) or decomposed under refluxing conditions (in the case of 5-azido-3-methyl-1-phenyl-1H-pyrazole-4-carbaldehyde).

The success in the synthesis of diketopiperazine-fused triazolobenzodiazepine prompted us to examine the possibility of making the sequential synthetic route in 'one-pot' starting from the Ugi 4-CR (Scheme 4). Thus we initiated the reaction sequence from the Ugi reaction in EtOH, after completion of which, the ring-closing steps (base induced and IAAC) were performed in succession. Unfortunately, the final products were obtained in slightly lower yields; $30 \%$ for $\mathbf{7 a}$ and $26 \%$ for $\mathbf{7 b}$, respectively.

Hydantoins belong to a unique class of heterocycles which can be found in a number of pharmaceuticals, cosmetics, insecticides, etc. [73-75]. These cyclic ureides are well known for 
<smiles>[R]c1cc(N)c(C=O)cc1[R]</smiles>

1a, $R^{1}, R^{2}=H$

1b, $\mathrm{R}^{1}=\mathrm{Br}, \mathrm{R}^{2}=\mathrm{H}$

1c, $\mathrm{R}^{1}=\mathrm{Cl}, \mathrm{R}^{2}=\mathrm{H}$

1d, $R^{1}, R^{2}=\mathrm{OMe}$<smiles>[R]C(Cl)C(=O)O</smiles>

3a, $\mathrm{R}=\mathrm{H}$

$3 b, R=M e$<smiles>[R]C#CC([R])([R3])N</smiles>

2a, $R^{3}, R^{4}=H$

2b, $R^{3}=M e, R^{4}=H$ 1. Ugi reaction

2c, $R^{3}=H, R^{4}=P h$

3. IAAC

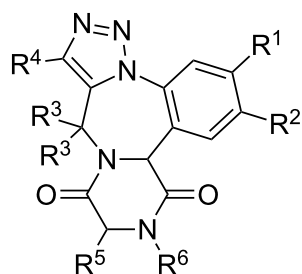

$7 a-1$

4a, $R^{4}=B n$

4b, $R^{4}=C y$

4c, $\mathrm{R}^{4}=t-\mathrm{Bu}$

4d, $\mathrm{R}^{4}=p-\mathrm{MeO}-\mathrm{Ph}$

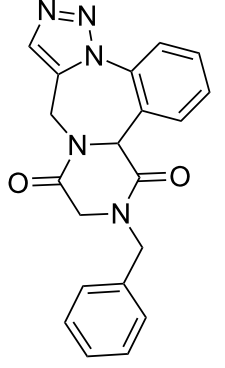

$7 a(37 \%)$<smiles>O=C1C2c3ccccc3-n3nncc3CN2C(=O)CN1C1CCCCC1</smiles>

$7 b(34 \%)$<smiles>CC(C)(C)N1CC(=O)N2Cc3cnnn3-c3ccccc3C2C1=O</smiles>

7c $(27 \%)$<smiles>COc1ccc(N2CC(=O)N3Cc4cnnn4-c4ccccc4C3C2=O)cc1</smiles>

7d $(67 \%)$

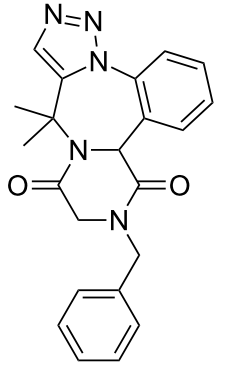

$7 e(60 \%)$<smiles>O=C1C2c3ccccc3-n3nnc(-c4ccccc4)c3CN2C(=O)CN1Cc1ccccc1</smiles>

$7 f(40 \%)$<smiles>O=C1C2c3ccc(Br)cc3-n3nncc3CN2C(=O)CN1Cc1ccccc1</smiles>

$7 g(57 \%)$<smiles>C[C@H]1C(=O)N2Cc3cnnn3-c3ccccc3C2C(=O)N1Cc1ccccc1</smiles>

7I (1:0.7, 41\%)<smiles>O=C1C2c3ccc(Br)cc3-n3nncc3CN2C(=O)CN1C1CCCCC1</smiles>

7h $(49 \%)$

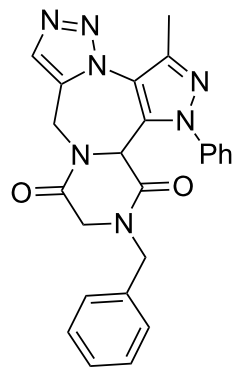

$7 \mathrm{~m}(0 \%)$

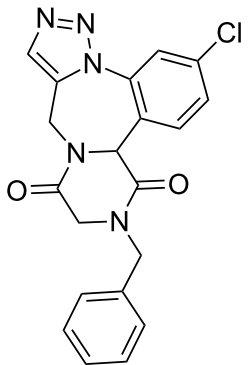

$7 \mathbf{i}(60 \%)$

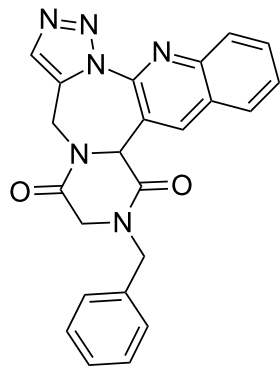

7n $(0 \%)$<smiles>O=C1CN(C2CCCCC2)C(=O)CN2Cc3cnnn3-c3cc(Cl)ccc3C12</smiles>

7j (54\%)

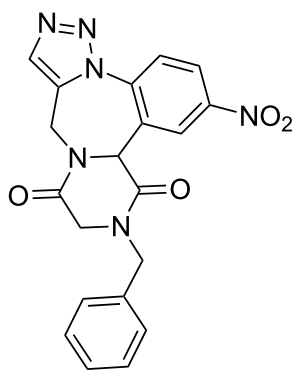

$70(0 \%)$<smiles>COc1cc2c(cc1OC)-n1nncc1CN1C(=O)CN(Cc3ccccc3)C(=O)C21</smiles>

$7 k(43 \%)$

Figure 2: Generality in the synthesis of diketopiperazine-fused triazolobenzodiazepine 7. Reaction conditions: 1. 2-azidobenzaldehyde 1 (1.85 mmol), propargylamine $2(1.85 \mathrm{mmol})$, chloroacetic acid $3(1.85 \mathrm{mmol})$, benzyl isocyanide $4(1.85 \mathrm{mmol}), 4 \AA \mathrm{MS}(100 \mathrm{mg}), \mathrm{EtOH}(7 \mathrm{~mL}), 20 \mathrm{~h}, \mathrm{rt}$; $2 . \mathrm{Ugi}$ adduct $5(0.26 \mathrm{mmol}), \mathrm{KOH}(0.28 \mathrm{mmol})$, ethanol $(1.5 \mathrm{~mL})$, sonication for 30 minutes, rt; 3 . neutralization with $1 \mathrm{M} \mathrm{HCl}, \mathrm{EtOH}(20 \mathrm{~mL})$ reflux, $3 \mathrm{~h}$. Overall yields for 3 steps are given for all the examples. 

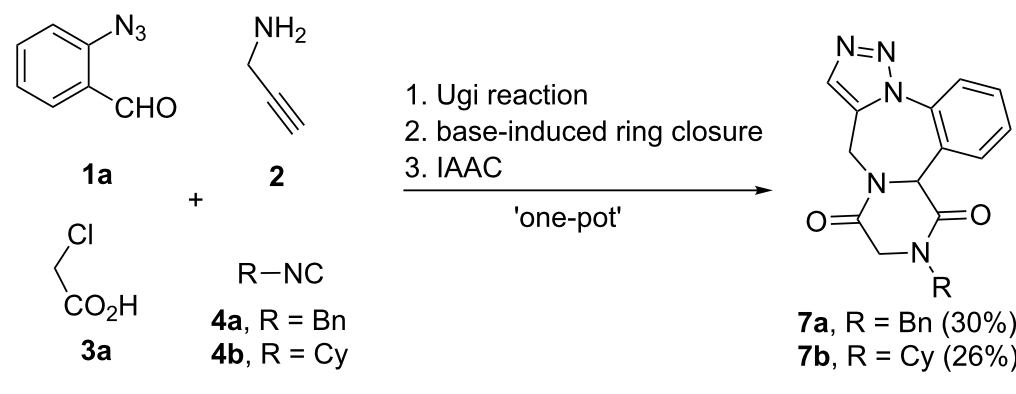

$7 a, R=B n(30 \%)$

$7 b, R=C y(26 \%)$

Scheme 4: 'One-pot' synthesis of diketopiperazine-fused triazolobenzodiazepines $7 \mathbf{a}$ and $\mathbf{7 b}$.

their anticonvulsant activity [76-78]. With the assumption that these molecules when fused to a benzodiazepine core would enhance the anticonvulsant activity, we undertook the synthesis of hydantoin-fused triazolobenzodiazepines starting from the Ugi reaction of $o$-azidobenzaldehyde (1a), propargylamine (2a), trichloroacetic acid (9) and benzyl isocyanide (4a, Scheme 5). The Ugi adduct was subjected to base-induced ring closing with $\mathrm{NaOEt}$ in EtOH which furnished the hydantoin intermediates; which on subsequent neutralization-dilution-IAAC afforded the expected hydantoin-fused benzodiazepine derivative 10a in $45 \%$ overall yield. In a similar way the cyclohexyl and $p$-methoxyphenyl-substituted compounds $\mathbf{1 0 b}$ and $10 \mathbf{c}$ were obtained in $82 \%$ and $62 \%$ overall yield, respectively.

The structure of hydantoin-fused triazolobenzodiazepine was confirmed by a X-ray crystal structure determination of 10a (Figure 3).

The three-step synthesis of heterocycle-fused triazolobenzodiazepines involves the well-known Ugi 4-CR as the first step and the IAAC as the last, the mechanisms of which are well established (Scheme 6). The second stage is the base-induced ring

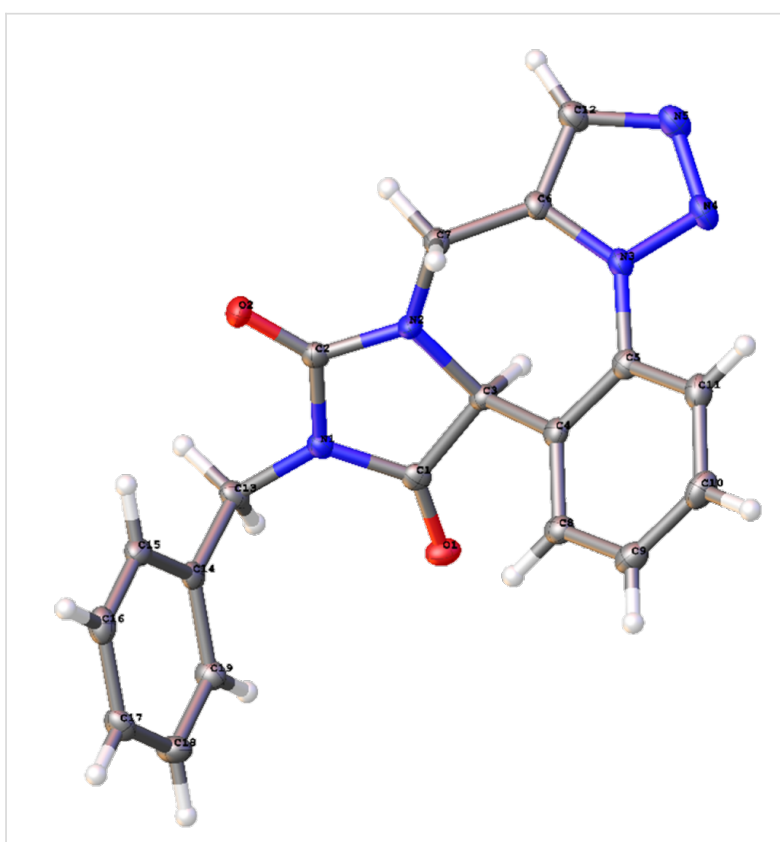

Figure 3: X-ray crystal structure of hydantoin-fused triazolobenzodiazepine 10a. (Displacement ellipsoids are drawn at the $30 \%$ probability level.)

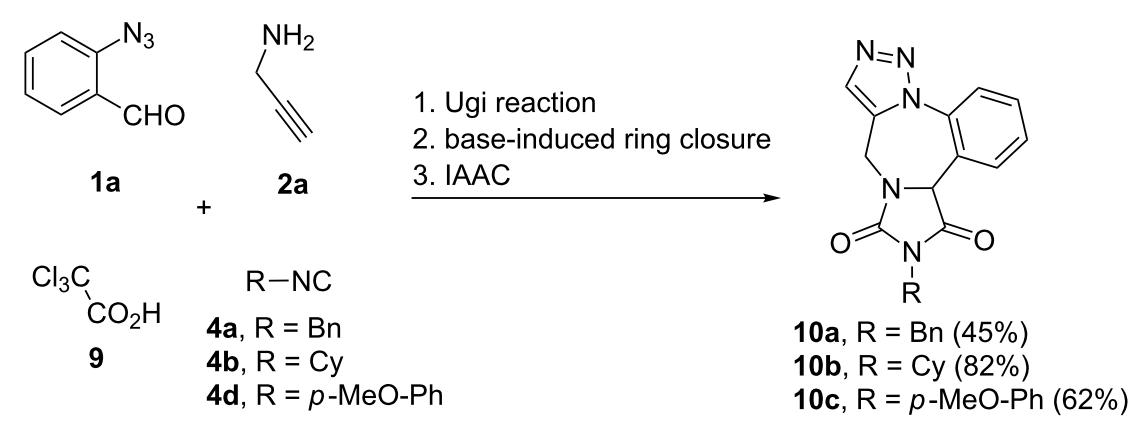

Scheme 5: Synthesis of hydantoin-fused triazolobenzodiazepine 10. Reaction conditions: 1. 2-azidobenzaldehyde 1 (1.85 mmol), propargylamine (2a, $1.85 \mathrm{mmol})$, trichloroacetic acid $(\mathbf{9}, 1.85 \mathrm{mmol})$, benzyl isocyanide 4 (1.85 mmol), $4 \AA \mathrm{MS}(100 \mathrm{mg})$, EtOH (7 mL), $20 \mathrm{~h}, \mathrm{rt}$; 2 . Ugi adduct 5 $(0.26 \mathrm{mmol})$, NaOEt $(0.28 \mathrm{mmol})$, ethanol $(1.5 \mathrm{~mL}), 30 \mathrm{~min}$, rt; 3 . neutralization with $1 \mathrm{M} \mathrm{HCl}, \mathrm{EtOH}(20 \mathrm{~mL})$ reflux, $3 \mathrm{~h}$. Overall yields for $3 \mathrm{steps}$ are given for all the examples. 


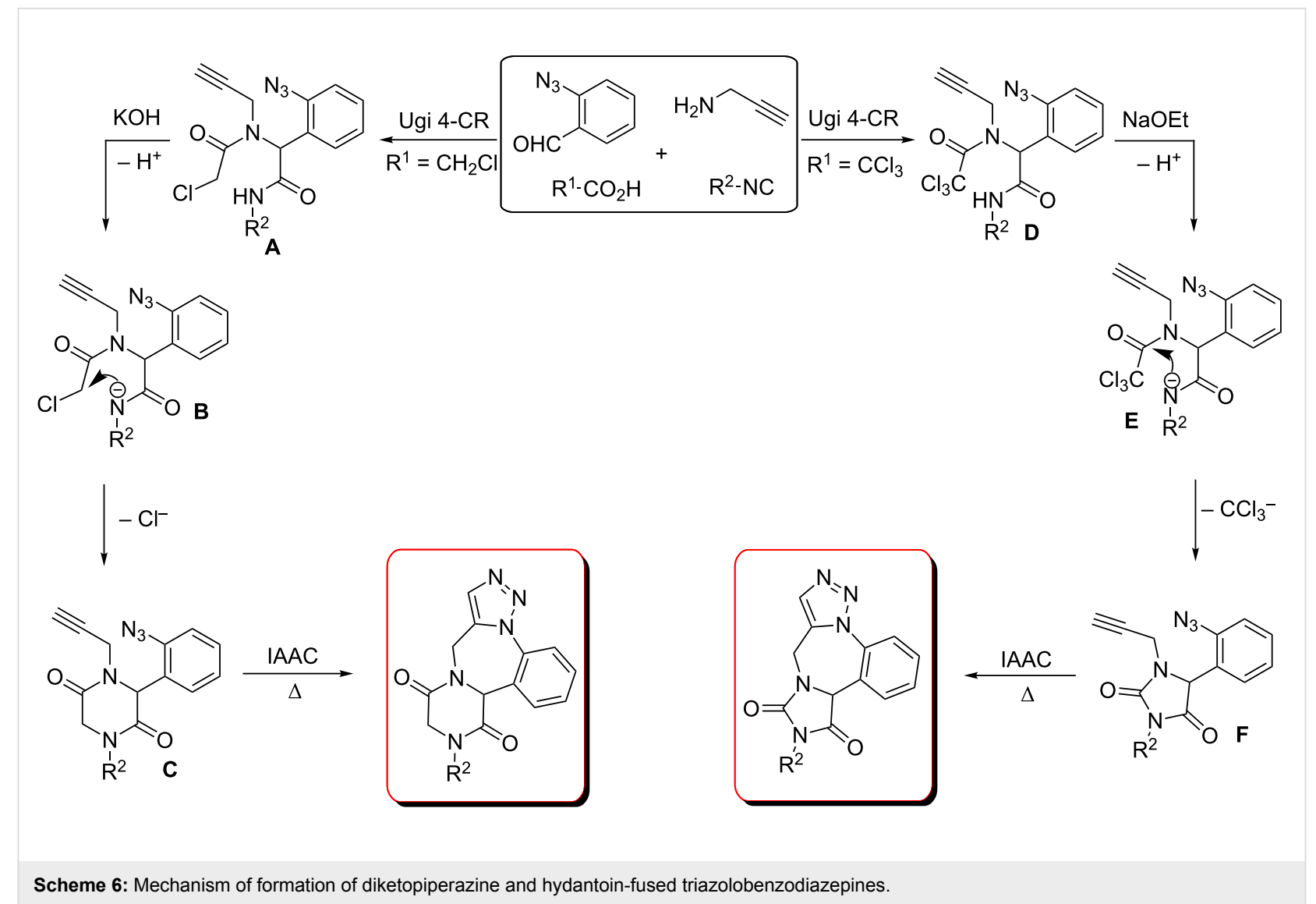

closing of the Ugi adduct $\mathbf{A}$ and $\mathbf{D}$ to the respective heterocycles. In the case of Ugi adduct $\mathbf{A}$, the base $(\mathrm{KOH})$ abstracts the amide hydrogen which attacks the methylene carbon (expelling a chloride ion) and thereby furnishing the 2,5-diketopiperazine ring $\mathbf{C}$. On the other hand, in the case of Ugi adduct $\mathbf{D}$, a base induced intramolecular nucleophilic attack of the amide $\mathrm{N}$-atom to the carbonyl carbon occurs (in intermediate $\mathbf{E}$ ) and the hydantoin ring $\mathbf{F}$ forms by the elimination of the trichloromethyl anion.

\section{Conclusion}

In conclusion, we have developed a sequential synthetic strategy to access diketopiperazine-fused triazolobenzodiazepines from simple starting materials. It is noteworthy to mention that halogenated (chloro and bromo) benzodiazepines could be synthesized following the developed protocol which might show analogues biological activity as that of halogenated triazolobenzodiazepine drugs available in market. We could also extend the strategy for the synthesis of hydantoin-fused triazolobenzodiazepines, other valuable multiring-fused heterocycles which might also exhibit potent bioactivities. The synthesized compounds are currently being evaluated for their biological properties, the results of which will be reported in due course.

\section{Supporting Information}

The Supporting Information features further experimental details, copies of ${ }^{1} \mathrm{H}$ and ${ }^{13} \mathrm{C}$ NMR spectra of compounds 5a, 6, 8, diketopiperazine-fused triazolobenzodiazepines 7 and hydantoin-fused triazolobenzodiazepines 10, and X-ray crystal structure details of $\mathbf{1 0 a}$.

\section{Supporting Information File 1}

Experimental part.

[https://www.beilstein-journals.org/bjoc/content/ supplementary/1860-5397-14-49-S1.pdf]

\section{Acknowledgements}

We thank the KU Leuven for financial support. Mass spectrometry was made possible by the support of the Hercules Foundation of the Flemish Government (grant 20100225-7). RV thanks the Fonds Wetenschappelijk Onderzoek - Vlaanderen (FWO) for a Ph.D. fellowship (1S13516N). JJ thanks the Department of Science and Technology (DST)-SERB, India, for a Young Scientist Start-Up Research Grant (SB/FT/CS-107/2014). LVM thanks the Hercules Foundation for supporting the purchase of the diffractometer (grant AKUL/09/0035). 


\section{ORCID ${ }^{\circledR}$ iDs}

Robby Vroemans - https://orcid.org/0000-0001-8641-6901 Jonas Winters - https://orcid.org/0000-0001-9625-1813 Jubi John - https://orcid.org/0000-0003-0483-2026 Wim Dehaen - https://orcid.org/0000-0002-9597-0629

\section{References}

1. Zhu, J.; Bienaymé, H., Eds. Multicomponent Reactions; Wiley-VCH: Weinheim, Germany, 2005. doi:10.1002/3527605118

2. Brauch, S.; van Berkel, S. S.; Westermann, B. Chem. Soc. Rev. 2013, 42, 4948-4962. doi:10.1039/c3cs35505e

3. Marcaccini, S.; Pepino, R.; Pozo, M. C. Tetrahedron Lett. 2001, 42, 2727-2728. doi:10.1016/S0040-4039(01)00232-5

4. Marcaccini, S.; Miliciani, M.; Pepino, R. Tetrahedron Lett. 2005, 46, 711-713. doi:10.1016/j.tetlet.2004.11.083

5. Ignacio, J. M.; Macho, S.; Marcaccini, S.; Pepino, R.; Torroba, T. Synlett 2005, 3051-3054. doi:10.1055/s-2005-922745

6. Marcaccini, S.; Torroba, T. Nat. Protoc. 2007, 2, 632-639. doi:10.1038/nprot.2007.71

7. Sunderhaus, J. D.; Dockendorff, C.; Martin, S. F. Org. Lett. 2007, 9 , 4223-4226. doi:10.1021/ol7018357

8. Hardy, S.; Martin, S. F. Org. Lett. 2011, 13, 3102-3105. doi:10.1021/ol201010s

9. Sañudo, M.; Garcia-Valverde, M.; Marcaccini, S.; Torroba, T. Tetrahedron 2012, 68, 2621-2629. doi:10.1016/j.tet.2012.01.073

10. Granger, B. A.; Wang, Z.; Kaneda, K.; Fang, Z.; Martin, S. F. ACS Comb. Sci. 2013, 15, 379-386. doi:10.1021/c0400055b

11. Moni, L.; Banfi, L.; Basso, A.; Carcone, L.; Rasparini, M.; Riva, R. J. Org. Chem. 2015, 80, 3411-3428. doi:10.1021/jo502829j

12. Akritopoulou-Zanze, I.; Gracias, V.; Djuric, S. W. Tetrahedron Lett. 2004, 45, 8439-8441. doi:10.1016/j.tetlet.2004.09.117

13. Gracias, V.; Darczak, D.; Gasiecki, A. F.; Djuric, S. W. Tetrahedron Lett. 2005, 46, 9053-9056. doi:10.1016/j.tetlet.2005.10.090

14. Pirali, T.; Tron, G. C.; Zhu, J. Org. Lett. 2006, 8, 4145-4148. doi:10.1021/ol061782p

15. Bahulayan, D.; Arun, S. Tetrahedron Lett. 2012, 53, 2850-2855. doi:10.1016/j.tetlet.2012.03.116

16. Dhondge, A. P.; Afraj, S. N.; Nuzlia, C.; Chen, C.; Lee, G.-H. Eur. J. Org. Chem. 2013, 4119-4130. doi:10.1002/ejoc.201300226

17. Nguyen, H. H.; Palazzo, T. A.; Kurth, M. J. Org. Lett. 2013, 15 , 4492-4495. doi:10.1021/ol402045h

18. Subba Reddy, B. V.; Majumder, N.; Prabhakar Rao, T. Synthesis 2014, 46, 3408-3414. doi:10.1055/s-0034-1379031

19. De Moliner, F.; Bigatti, M.; De Rosa, C.; Banfi, L.; Riva, R.; Basso, A. Mol. Diversity 2014, 18, 473-482. doi:10.1007/s11030-014-9530-x

20. De Moliner, F.; Bigatti, M.; Banfi, L.; Riva, R.; Basso, A. Org. Lett. 2014, 16, 2280-2283. doi:10.1021/ol500813p

21. Barlow, T. M. A.; Jida, M.; Tourwé, D.; Ballet, S. Org. Biomol. Chem. 2014, 12, 6986-6989. doi:10.1039/C4OB01381F

22. Salvador, C. E. M.; Pieber, B.; Neu, P. M.; Torvisco, A.; Andrade, C. K. Z.; Kappe, C. O. J. Org. Chem. 2015, 80, 4590-4602. doi:10.1021/acs.joc.5b00445

23. Raj, P. J.; Bahulayan, D. Tetrahedron Lett. 2015, 56, 2451-2455 doi:10.1016/j.tetlet.2015.03.081

24. Keating, T. A.; Armstrong, R. W. J. Am. Chem. Soc. 1996, 118 2574-2583. doi:10.1021/ja953868b
25. Keating, T. A.; Armstrong, R. W. J. Org. Chem. 1996, 61, 8935-8939. doi:10.1021/jo961517p

26. Attwood, D.; Gibson, J. J. Pharm. Pharmacol. 1978, 30, 176-180. doi:10.1111/j.2042-7158.1978.tb13192.x

27. Chakrabarti, J. K.; Hotten, T. M.; Pullar, I. A.; Steggles, D. J. J. Med. Chem. 1989, 32, 2375-2381. doi:10.1021/jm00130a025

28. Hsu, M. C.; Schutt, A. D.; Holly, M.; Slice, L. W.; Sherman, M. I.; Richman, D. D.; Potash, M. J.; Volsky, D. J. Science 1991, 254, 1799-1802. doi:10.1126/science.1763331

29. Liegeois, J. F. F.; Bruhwyler, J.; Damas, J.; Nguyen, T. P.; Chleide, E. M. G.; Mercier, M. G. A.; Rogister, F. A.; Delarge, J. E. J. Med. Chem. 1993, 36, 2107-2114. doi:10.1021/jm00067a009

30. Liegeois, J. F. F.; Rogister, F. A.; Bruhwyler, J.; Damas, J.; Nguyen, T. P.; Inarejos, M. O.; Chleide, E. M. G.; Mercier, M. G. A.; Delarge, J. E. J. Med. Chem. 1994, 37, 519-525. doi:10.1021/jm00030a011

31. Ballard, C. G.; O'Brien, J. T.; Swann, A. G.; Thompson, P.; Neill, D.; McKeith, I. G. J. Clin. Psychiatry 2001, 62, 46. doi:10.4088/JCP.v62n0110

32. Nierenberg, A. A.; Gray, S. M.; Grandin, L. D. J. Clin. Psychiatry 2001, 62 (Suppl. 25), 27-30.

33. Hanley, D. F., Jr.; Pozo, M. Int. J. Clin. Pract. 2000, 54, 30-35.

34. Zahradník, I.; Minarovič, I.; Zahradníková, A. J. Pharmacol. Exp. Ther. 2008, 324, 977-984. doi:10.1124/jpet.107.132456

35. Coyne, W. E.; Cusic, J. W. J. Med. Chem. 1967, 10, 541-546. doi:10.1021/jm00316a009

36. Wright, W. B., Jr.; Brabander, H. J.; Greenblatt, E. N.; Day, I. P.; Hardy, R. A., Jr. J. Med. Chem. 1978, 21, 1087-1089. doi:10.1021/jm00208a017

37. Horton, D. A.; Bourne, G. T.; Smythe, M. L. Chem. Rev. 2003, 103 893-930. doi:10.1021/cr020033s

38. Kamal, A.; Shetti, R. V. C. R. N. C.; Ramaiah, M. J.; Swapna, P.; Reddy, K. S.; Mallareddy, A.; Rao, M. P. N.; Chourasia, M.; Sastry, G. N.; Juvekar, A.; Zingde, S.; Sarma, P.; Pushpavalli, S. N. C. V. L.; Pal-Bhadra, M. MedChemComm 2011, 2 , 780-788. doi:10.1039/c1md00072a

39. Gill, R. K.; Kaushik, S. O.; Chugh, J.; Bansal, S.; Shah, A.; Bariwal, J. Mini-Rev. Med. Chem. 2014, 14, 229-256. doi:10.2174/13895575113139990081

40. Vitaku, E.; Smith, D. T.; Njardarson, J. T. J. Med. Chem. 2014, 57, 10257-10274. doi:10.1021/jm501100b

41. Maheshwari, N.; Goyal, A.; Jain, S.; Jain, D.; Moorthy, N. S. H. N. Med. Chem. Res. 2014, 23, 765-774. doi:10.1007/s00044-013-0675-4

42. Thurston, D. E.; Vassoler, H.; Jackson, P. J. M.; James, C. H.; Rahman, K. M. Org. Biomol. Chem. 2015, 13, 4031-4040. doi:10.1039/C4OB02405B

43. Ripka, W. C.; De Lucca, G. V.; Bach, A. C., II; Pottorf, R. S.; Blaney, J. M. Tetrahedron 1993, 49, 3593-3608. doi:10.1016/S0040-4020(01)90217-0

44. Ripka, A. S.; Rich, D. H. Curr. Opin. Chem. Biol. 1998, 2, 441-452. doi:10.1016/S1367-5931(98)80119-1

45. Hata, M.; Marshall, G. R. J. Comput.-Aided Mol. Des. 2006, 20, 321-331. doi:10.1007/s10822-006-9059-x

46. Mohler, H.; Okada, T. Science 1977, 198, 849-851. doi:10.1126/science. 918669

47. Braestrup, C.; Schmiechen, R.; Neef, G.; Nielsen, M.; Petersen, E. N. Science 1982, 216, 1241-1243. doi:10.1126/science.6281892

48. Rudolph, U.; Knoflach, F. Nat. Rev. Drug Discovery 2011, 10, 685-697. doi:10.1038/nrd3502 
49. Scharf, M. B.; Roth, P. B.; Dominguez, R. A.; Ware, J. C. J. Clin. Pharmacol. 1990, 30, 461-467. doi:10.1002/j.1552-4604.1990.tb03486.x

50. Post, G. L.; Patrick, R. O.; Crowder, J. E.; Houston, J.; Ferguson, J. M.; Bielski, R. J.; Bailey, L.; Pearlman, H. G.; Shu, V. S.; Pierce, M. W. J. Clin. Psychopharmacol. 1991, 11, 249-253. doi:10.1097/00004714-199108000-00005

51. Gerecke, M.; Kyburz, E.; Borer, R.; Gassner, W. Heterocycles 1994, 39, 693-721. doi:10.3987/COM-94-S(B)61

52. Levine, J.; Cole, D. P.; Chengappa, K. N. R.; Gershon, S. Depression Anxiety 2001, 14, 94-104. doi:10.1002/da.1051

53. Snyder, P. J.; Werth, J.; Giordani, B.; Caveney, A. F.; Feltner, D.; Maruff, P. Hum. Psychopharmacol. Clin. Exp. 2005, 20, 263-273. doi:10.1002/hup.692

54. Alajarín, M.; Cabrera, J.; Pastor, A.; Villalgordo, J. M. Tetrahedron Lett. 2007, 48, 3495-3499. doi:10.1016/j.tetlet.2007.03.121

55. Mohapatra, D. K.; Maity, P. K.; Shabab, M.; Khan, M. I. Bioorg. Med. Chem. Lett. 2009, 19, 5241-5245. doi:10.1016/j.bmcl.2009.06.107

56. Martins, M. B.; Carvalho, I. Tetrahedron 2007, 63, 9923-9932. doi:10.1016/j.tet.2007.04.105

57. Hulme, C.; Morrissette, M. M.; Volz, F. A.; Burns, C. J. Tetrahedron Lett. 1998, 39, 1113-1116. doi:10.1016/S0040-4039(97)10795-X

58. Nixey, T.; Kelly, M.; Hulme, C. Tetrahedron Lett. 2000, 41, 8729-8733. doi:10.1016/S0040-4039(00)01563-X

59. Merckx, T.; Verwilst, P.; Dehaen, W. Tetrahedron Lett. 2013, 54, 4237-4240. doi:10.1016/j.tetlet.2013.05.133

60. Thomas, J.; John, J.; Parekh, N.; Dehaen, W. Angew. Chem., Int. Ed. 2014, 53, 10155-10159. doi:10.1002/anie.201403453

61. Efimov, I.; Bakulev, V.; Beliaev, N.; Beryozkina, T.; Knippschild, U.; Leban, J.; Zhi-Jin, F.; Eltsov, O.; Slepukhin, P.; Ezhikova, M.; Dehaen, W. Eur. J. Org. Chem. 2014, 3684-3689. doi:10.1002/ejoc.201402130

62. Merckx, T.; Haynes, C. J. E.; Karagiannidis, L. E.; Clarke, H. J.; Holder, K.; Kelly, A.; Tizzard, G. J.; Coles, S. J.; Verwilst, P.; Gale, P. A.; Dehaen, W. Org. Biomol. Chem. 2015, 13, 1654-1661. doi:10.1039/C4OB02236J

63. John, J.; Thomas, J.; Parekh, N.; Dehaen, W. Eur. J. Org. Chem. 2015, 4922-4930. doi:10.1002/ejoc.201500459

64. Beryozkina, T. V.; Efimov, I. V.; Fabian, W. M. F.; Beliaev, N. A.; Slepukhin, P. A.; Isenov, M. L.; Dehaen, W.; Lubec, G.; Eltsov, O. S.; Fan, Z.; Thomas, J.; Bakulev, V. A. Tetrahedron 2015, 71, 6189-6195. doi:10.1016/j.tet.2015.06.088

65. John, J.; Thomas, J.; Dehaen, W. Chem. Commun. 2015, 51, 10797-10806. doi:10.1039/C5CC02319J

66. Thomas, J.; Jana, S.; John, J.; Liekens, S.; Dehaen, W. Chem. Commun. 2016, 52, 2885-2888. doi:10.1039/C5CC08347H

67. Verbelen, B.; Dehaen, W. Org. Lett. 2016, 18, 6412-6415. doi:10.1021/acs.orglett.6b03309

68. Thomas, J.; Goyvaerts, V.; Liekens, S.; Dehaen, W. Chem. - Eur. J. 2016, 22, 9966-9970. doi:10.1002/chem.201601928

69. Jana, S.; Thomas, J.; Dehaen, W. J. Org. Chem. 2016, 81, 12426-12432. doi:10.1021/acs.joc.6b02607

70. Jalani, H. B.; Karagöz, A. C.; Tsogoeva, S. V. Synthesis 2016, 49, 29-41. doi:10.1055/s-0036-1588904

71. Raiguel, S.; Depuydt, D.; Vander Hoogerstraete, T.; Thomas, J.; Dehaen, W.; Binnemans, K. Dalton Trans. 2017, 46, 5269-5278. doi:10.1039/C7DT00624A
72. Jana, S.; Iram, S.; Thomas, J.; Hayat, M. Q.; Pannecouque, C.; Dehaen, W. Molecules 2017, 22, 303. doi:10.3390/molecules22020303 73. Ware, E. Chem. Rev. 1950, 46, 403-470. doi:10.1021/cr60145a001

74. Avendaño López, C.; González Trigo, G. Adv. Heterocycl. Chem. 1985, 38, 177-228. doi:10.1016/S0065-2725(08)60920-4

75. Meusel, M.; Gütschow, M. Org. Prep. Proced. Int. 2004, 36, 391-443. doi:10.1080/00304940409356627

76. Mehta, N. B.; Diuguid, C. A. R.; Soroko, F. E. J. Med. Chem. 1981, 24, 465-468. doi:10.1021/jm00136a018

77. Kutt, H.; Harden, C. L. Phenytoin and Congeners. In Antiepileptic Drugs; Eadie, M. J.; Vajda, F. J. E., Eds.; Handb. Exp. Pharmacol., Vol. 138; Springer: Berlin, Heidelberg, 1999; pp 229-265. doi:10.1007/978-3-642-60072-2_9

78. Rogawski, M. A.; Löscher, W. Nat. Rev. Neurosci. 2004, 5, 553-564. doi:10.1038/nrn1430

\section{License and Terms}

This is an Open Access article under the terms of the Creative Commons Attribution License (http://creativecommons.org/licenses/by/4.0), which permits unrestricted use, distribution, and reproduction in any medium, provided the original work is properly cited.

The license is subject to the Beilstein Journal of Organic Chemistry terms and conditions: (https://www.beilstein-journals.org/bjoc)

The definitive version of this article is the electronic one which can be found at: doi:10.3762/bjoc. 14.49 